\title{
ANÁLISE INTEGRADA DO USO DA TERRA E GEOMORFOLOGIA DO BIOMA CERRADO: UM ESTUDO DE CASO PARA GOIÁS
}

\author{
Thiago Morato de Carvalho', Manuel Eduardo Ferreira e Maximiliano Bayer \\ Artigo recebido em 08/09/2008 e aceito em 03/11/2008
}

\begin{abstract}
RESUMO
Cerrado ainda se encontra pouco valorizado em termos de conservação. Estudos recentes, com base em dados de Sensoriamento Remoto, apontam um estágio de conversão deste bioma na ordem de $50 \%$, degradação esta normalmente relacionada às atividades de pastoreio, agricultura, mineração, hidroelétricas e carvoarias. Insere-se ai a proposta geral deste artigo, a qual é, ainda que de forma preliminar, relacionar os aspectos físicos da paisagem, representados aqui pelas unidades geomorfológicas de relevo, com o processo de ocupação da fronteira agropecuária no Estado de Goiás. Dentre os objetivos específicos, busca-se quantificar e compreender a distribuição dos remanescentes de Cerrado e classes de uso do solo para as diversas categorias geomorfológicas no Estado.
\end{abstract}

Palavras-chave: cerrado, conservação, geomorfologia, vegetação, sensoriamento remoto.

\section{INTEGRATED ANALYSIS OF THE USE OF LAND AND GEOMORFOLOGIA CERRADO BIOMA: A CASE STUDY FOR GOIÁS}

\begin{abstract}
Cerrado is still little investment in conservation. Recent studies, based on data of Remote Sensing, pointed a stage of conversion of this biome in the order of $50 \%$, this degradation usually related to the activities of grazing, agriculture, mining, hydroelectric and carvoarias. It is ai the general proposal of this article, which is that, albeit preliminary, linking the physical aspects of the landscape, represented here by units geomorphological relief, with the process of occupation of the border farming in the State of Goiás Among specific objectives, seeks to quantify and understand the distribution of the remnants of Cerrado and classes to use the land for the various categories geomorphological in the State.

Keywords: Cerrado, conservation, geomorphology, vegetation, remote sensing.
\end{abstract}

${ }^{1}$ Geomorfólogo, pesquisador do BIOSE - Biodiversidade de Sergipe - Universidade Federal de Sergipe. tmorato@infonet.com.br 


\section{INTRODUÇÃO}

A região de Cerrado, ocupa uma extensa área no país ( $25 \%$ do território), fazendo limite com todos os grandes ecossistemas brasileiros: ao norte com a Amazônia, a nordeste com a Caatinga, a leste e sudeste com a Mata Atlântica, a oeste com o Pantanal e ao sul com os Pampas Sulinos.

A biodiversidade neste bioma recebe um destaque mundial, com a presença de uma vasta flora e fauna, em parte desconhecidas, marcadas por um forte endemismo (MYERS, 2000; ARRUDA, 2001). A riqueza de espécies e paisagens se deve, sobretudo, pela presença das referidas áreas de ecótonos, assim como pelas nascentes de três das maiores bacias hidrográficas da América do Sul encontradas na área core do cerrado (Paraguai-Paraná, Araguaia-Tocantins e São Francisco) (EITEN, 1993; RATTER et al., 1996), responsáveis pela formação de alguns dos grandes rios brasileiros (Fig. 1).

Apesar da comprovada importância sócio-ambiental, o Cerrado ainda se encontra pouco valorizado em termos de conservação. Estudos recentes, com base em dados de Sensoriamento Remoto, apontam um estágio de conversão deste bioma na ordem de 50\%, degradação esta normalmente relacionada às atividades de pastoreio, agricultura, mineração, hidroelétricas e carvoarias (MACHADO et al., 2004). Ainda que divergentes, as estimativas revelam um intenso processo de ocupação, iniciado entre as décadas de 1950 e 1960.

Dentre os fatores que continuam a propiciar esta ocupação, em geral pouco planejada, destacam-se os (1) motivos econômicos (terras mais baratas, incentivos governamentais e proximidade de mercados consumidores), (2) culturais (uso indiscriminado dos recursos naturais, com práticas agrícolas inadequadas), e (3) físiconaturais (disponibilidade de recursos hídricos e terras planas para a agricultura mecanizada). Todos estes fatores acabam por induzir o surgimento de distúrbios ambientais graves, com reflexo imediato em toda a paisagem, incluindo a própria fauna e flora da região. No caso de Goiás, único Estado da Federação totalmente inserido na área core do Cerrado, o cenário de degradação é mais preocupante. $\mathrm{O}$ último mapeamento demonstra uma taxa de conversão da cobertura nativa na ordem de $64 \%$, fortemente marcadas pela expansão da pecuária e pela tecnificação da agricultura (FERREIRA et al., 2005).

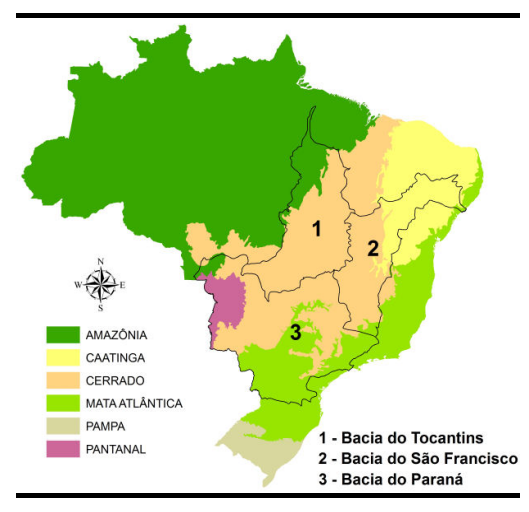

Figura 1 - Limite do bioma Cerrado com os demais ecossistemas no Brasil, com destaque para três grandes bacias hidrográficas da 
América do Sul, cujas nascentes encontram-se na área core do Cerrado.

Por outro lado, e embora conhecidos, ainda persiste um desentendimento sobre os processos de ocupação do cerrado. Normalmente, os estudos sobre a conversão dos remanescentes vegetacionais não são realizados numa perspectiva que leve em conta a geomorfologia e geologia da região, ou seja, os limitantes naturais para o uso da terra. Os poucos estudos nesta direção são bastante pontuais, e voltados para o setor agrícola, onde a única variável considerada têm sido as propriedades do solo e sua capacidade de uso para tais fins. Na outra ponta desta discussão está a abordagem sócio-econômica, também incompleta, a qual define a expansão das fronteiras agrícolas como um processo movido por forças econômicas e sociais, quando a transformação da paisagem é orientada, sobretudo, por categorias de relevo.

Insere-se ai a proposta geral deste artigo, a qual é, ainda que de forma preliminar, relacionar os aspectos físicos da paisagem, representados aqui pelas unidades geomorfológicas de relevo, com o processo de ocupação da fronteira agropecuária no Estado de Goiás. Dentre os objetivos específicos, busca-se quantificar e compreender a distribuição dos remanescentes de Cerrado e classes de uso do solo para as diversas categorias geomorfológicas no Estado.

Carvalho, T. M. de, Ferreira, M. E. Bayer, M.

\section{MATERIAIS E MÉTODOS}

A área de estudo abrange o Estado de Goiás e o Distrito Federal, totalizando uma área aproximada de $340 \mathrm{mil} \mathrm{km}^{2}$. Na figura 2 estão demonstradas as áreas convertidas no Estado (64\%), as áreas de remanescentes de Cerrado, unidades de conservação e áreas prioritárias para a conservação da biodiversidade.

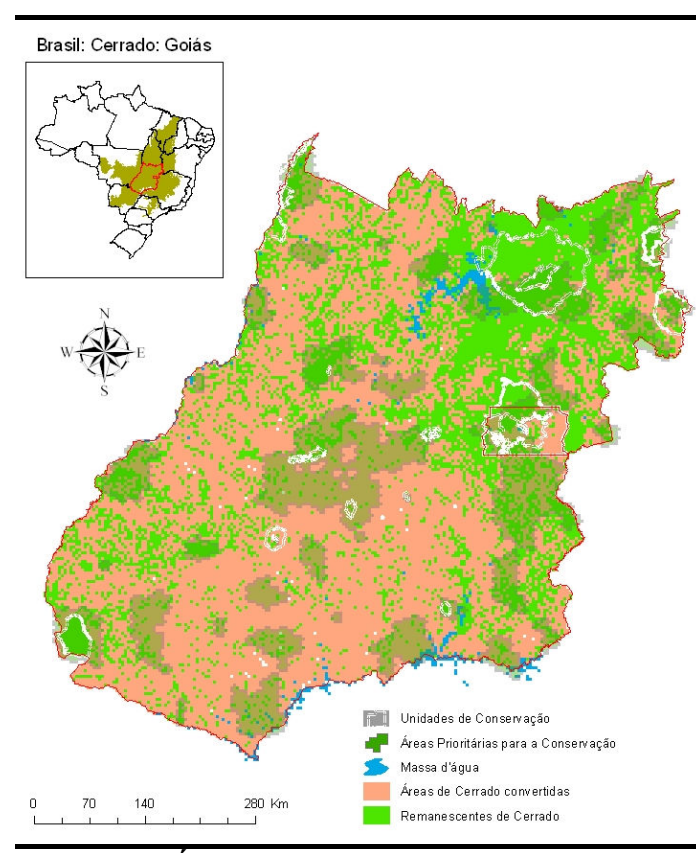

Figura 2 - Área de estudo, com destaque para as áreas convertidas, os remanescentes de Cerrado, as unidades de conservação e as áreas prioritárias para a conservação.

\section{Base de dados}

Atualmente, Goiás conta com uma ampla base de dados digital gerada por orgãos tecnicos do governo do Estado, fundamentalmente disponíveis no SIGGoias/SIEG (www.sieg.go.gov.br) e na Universidade Federal de Goiás, particularmente no Laboratório de 
Processamento de Imagens e Geoprocessamento _ _ $\quad$ LAPIG (www.ufg.br/lapig), incluindo recentes mapeamentos dos remanescentes de Cerrado e das unidades geomorfológicas do relevo goiano (MOREIRA E FERREIRA, 2006; LATRUBESSE E CARVALHO, 2006; CARVALHO, 2007). Tais bases são imprescindíveis para o entendimento e ordenamento territorial do uso do solo na região. Para a realização deste estudo, foram empregues as bases de dados detalhadas na seqüência, e ilustradas pela figura 3. Cabe destacar que os autores deste artigo foram envolvidos, direta ou indiretamente, na geração de todos os produtos abaixo mencionados.

1) Mapa de Remanescentes e Uso do Solo do Estado de Goiás, produzido com base na interpretação de imagens de satélite (sensor Landsat-TM, 2002) e em trabalhos de campo, sob coordenação da Agência Goiana de Meio Ambiente (AGMA);

2) Mapa Geomorfológico do Estado de Goiás, produzido para a série Geologia e Mineração de Goiás e Distrito Federal (Superintendência de Geologia e Mineração), com base na interpretação de imagens de satélite (sensor Landsat-TM), juntamente com dados altimétricos da superfície (NASA/SRTM) e trabalhos de campo, sob coordenação do Laboratório de Geologia e Geografia Física

Carvalho, T. M. de, Ferreira, M. E. Bayer, M.
(LABOGGEF) da Universidade Federal de Goiás;

3) Mosaico de Imagens SRTM (Suttle Radar Topography Mission) para o Estado de Goiás, empregada na modelagem topográfica do território goiano. Com base no SRTM, foi gerado o mapa de declividade e transectos explicativos sobre o relevo da região, informações estas fundamentais para o entendimento da geomorfologia em Goiás.

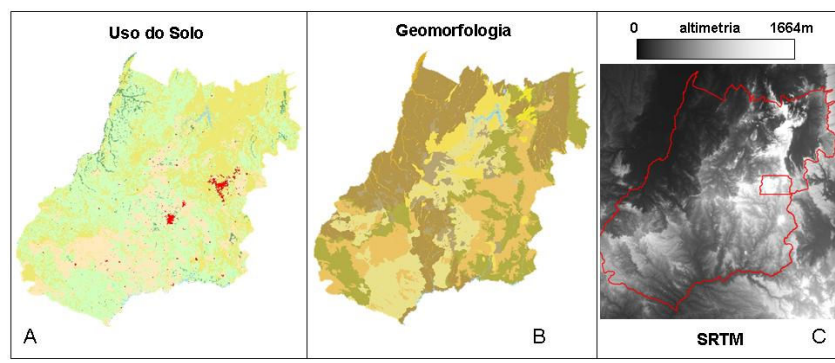

Figura 3 - Principais bases de dados empregadas neste estudo. (A) Mapa de remanescentes vegetais e uso solo; (B) Mapa Geomorfológico; (C) Imagem SRTM (altimetria e declividade).

Diagnóstico da cobertura vegetal remanescente e análise fFitogeomorfológica

Para a etapa de diagnóstico dos remanescentes de Cerrado no Estado de Goiás, foi utilizado o Índice Normalizado de Remanescentes (INR), demonstrado por Ferreira et. al. (2006), o qual indica, numa escala de -1 a 1, a ausência ou a presença de remanescentes em uma dada área geográfica (municípios, bacias hidrográficas, etc.) e, consequentemente, o seu respectivo grau de preservação. Neste artigo, a análise do INR foi aplicada aos municípios goianos, de forma 
que, com um INR negativo o município estaria, por exemplo, com uma área de uso do solo superior à área de remanescentes, e viceversa. Na equação abaixo (Eq. 1) são demonstrados as operações para a obtenção do INR.

$$
I N R=\frac{A R t-A U t}{A R t+A U t} \quad \text { (Eq. 1) }
$$

Onde:

INR: Índice de Remanescente

ARt: Área de Remanescente total do município $A U t$ : Área de Uso total do município

$\mathrm{Na}$ etapa de análise da fitogeomorfologia em Goiás, o Mapa Geomorfológico do Estado de Goiás e do Distrito Federal foi intersectado com o Mapa de Uso da Terra e Remanescentes de Cerrado, ambos à escala de 1:250.000, num ambiente de SIG (Sistema de Informações Geográficas). Com base neste procedimento, foi possível identificar a relação das grandes unidades de relevo do Estado com as fisionomias de Cerrado e classes de uso antrópico mais comuns.

\section{Unidades geomorfológicas em Goiás}

A geomorfologia do Estado de Goiás apresenta uma expressiva predominância de formas denudacionais, isto é, com elevada perda de solo por processos erosivos, chegando a ocupar $98 \%$ de sua superfície. Por outro lado, os sistemas agradacionais, ou seja, aqueles responsáveis pela formação de solos Carvalho, T. M. de, Ferreira, M. E. Bayer, M. constituem, aproximadamente, 1,7\% da área, sendo representados exclusivamente por sistemas de agradação fluvial (Planícies Fluviais - PF) e lacustre (LA).

As formas denudacionais têm sido identificadas e classificadas nas seguintes categorias: Superfícies Regionais de Aplainamento (SRA); Zonas de Erosão Recuante (ZER); Morros e Colinas (MC), com ou sem controle estrutural; Hogbacks (HB), isto é, superfícies bastante inclinadas geradas por processos de dobramentos, formando colinas e morros; Braquianticlinais (BQ), isto é, dobramentos associados a corpos intrusivos plutônicos; Formas dômicas (DM) geradas por blocos falhados; Pseudo-domos (PSD) geradas por estruturas tectônicas complexas sobre rochas pré-cambrianas; Relevos tabulares (RT) geradas sobre rochas sedimentares horizontais e sub-horizontais, geralmente relacionados com a formação de algumas Superfícies Regionais de Aplainamento e Relevos cársticos.

Para este artigo, as formas denudacionais (descritas acima) foram agrupadas em oito classes de análise: Superfície Regional de Aplainamento (SRA) I (mais antiga), II, III e VI (mais nova), Zona de Erosão Recuante (ZER), Morros e Colinas (MC), Estruturais e Agradação. O mapa na figura 4 ilustra a distribuição destas unidades geomorfológicas no Estado de Goiás.

Da mesma forma, para a análise integrada entre remanescentes e unidade 
geomorfológica, as classes de Cerrado foram agrupadas em três grupos de análise: (1) Estrato herbáceo-arbustivo (Campo limpo/Campo sujo, incluindo áreas de veredas e campos com murundus); (2) Estrato arbóreo (Transição Campo sujo/Cerrado ralo e Cerrado típico/denso); (3) Estrato florestal (Cerradão, Mata de Galeria e Floresta estacional). Quanto às classes de uso da terra, estas foram agrupadas em Agricultura, Pastagem, Área urbana e Mineração (Além de massas d'água). Esta simplificação de classes visa a uma maior objetividade às análises em questão.

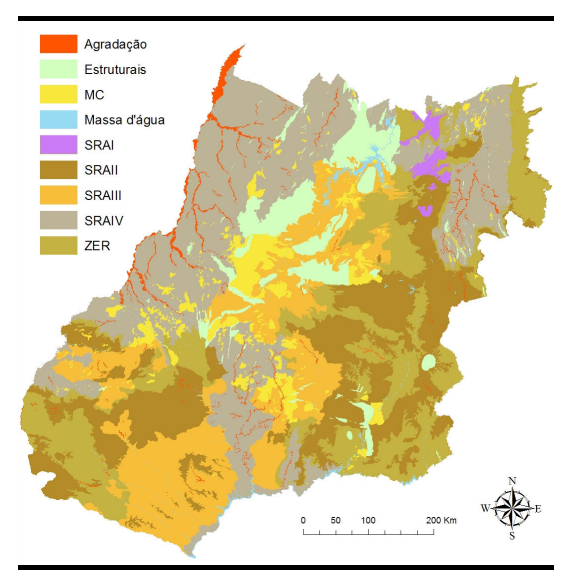

Figura 4 - Mapa geomorfológico para o Estado de Goiás (categorias gerais).

\section{RESULTADOS E DISCUSSÕES}

\section{Estágio de conservação do Cerrado goiano}

O atual mapa de cobertura vegetal e uso do solo para Goiás (ano-base 2002) indica que 64\% da vegetação nativa de Cerrado já foram convertidas em atividades agropecuárias (agricultura e pastagem), áreas urbanas e outras formas de uso, tais como áreas urbanas e mineração. O mapa retratado na figura 5 ilustra as regiões no Estado mais conservadas Carvalho, T. M. de, Ferreira, M. E. Bayer, M. em termos de remanescentes de Cerrado e aquelas mais degradadas.

Em termos quantitativos, atualmente 45\% da área do Estado apresentam-se na forma de pastagens (nativas e cultivadas), atuando como o principal vetor para a expansão da fronteira agrícola em Goiás. A classes de uso Agricultura ocupa 18\%, seguido pela classe urbana, ainda inferior a $1 \%$ do Estado.

Por outro lado, os remanescentes de Cerrado estão presentes numa área significativa em Goiás (33\%), embora praticamente metade destes remanescentes já esteja comprometida em termos ecológicos, sobretudo pela ameaça de novos desmatamentos e pela elevada fragmentação da paisagem. A Figura 6 ilustra, em termos quantitativos, a distribuição destas classes de cobertura do solo.

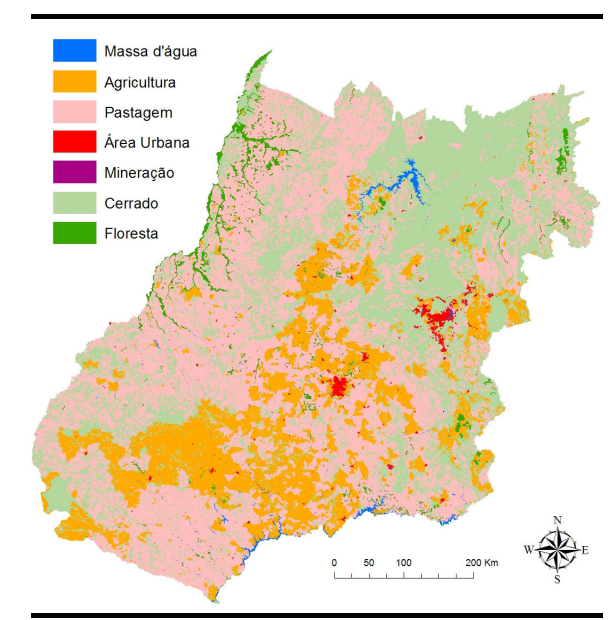

Figura 5 - Distribuição quantitativa (\%) das classes de cobertura do solo em Goiás. 


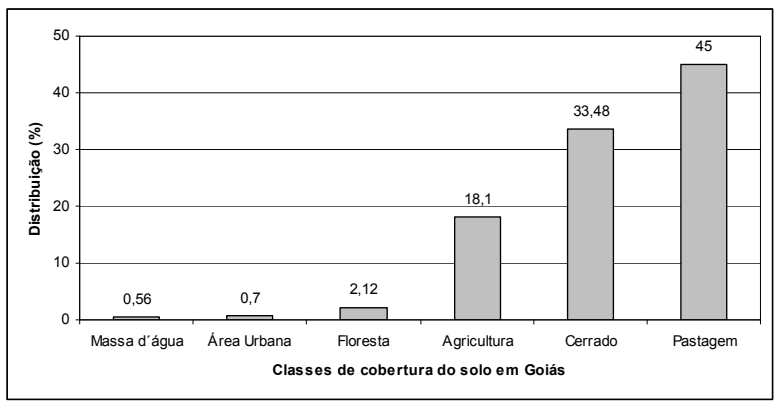

Figura 6 - Distribuição quantitativa das classes de cobertura do solo em Goiás.

Em termos municipais, a distribuição dos remanescentes de Cerrado é bastante crítica. Entre os 246 municípios, $210 \quad$ (85\%) apresentam uma área convertida superior à área de remanescentes, ou seja, com um INR negativo (Figura 7).

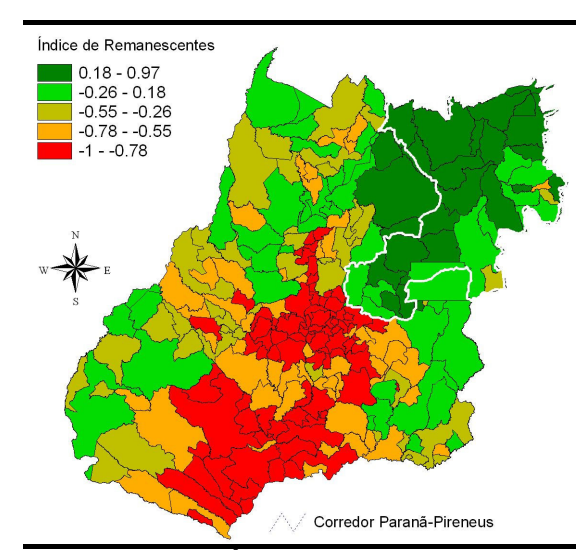

Figura 7 - Índice Normalizado de Remanescentes (INR) para o Estado de Goiás, no qual valores negativos indicam área de remanescente inferior à área convertida (tons de laranja e vermelho), e vice-versa. Fonte: Ferreira et al. (2006).

De uma forma geral, as meso-regiões Sul e Centro Goiano apresentam um elevado número de municípios com INR negativo, variando de $-0,78$ a -1 (Figura 7), tendência também observada para as demais regiões, com exceção do Nordeste de Goiás, ainda caracterizado pelo domínio de áreas Carvalho, T. M. de, Ferreira, M. E. Bayer, M. preservadas. Na Tabela 1 são enumerados, à título de exemplo, os 10 municípios com uma situação mais crítica em termos de preservação do Cerrado.

Ainda em relação aos dados apresentados na Figura 7, é importante ressaltar que a área escolhida para o projeto Corredor Ecológico Paraná-Pireneus foi bastante adequada, sobretudo porque os municípios com o INR positivo estão, em sua maioria, presentes neste limite geográfico. Tais municípios, com uma área média de remanescentes superior à área de uso do solo, somam 36 (15\%) (tons de verde na Figura 7). O relevo movimentado nesta área, com acentuada declividade, tem contido o avanço de atividades potencialmente degradantes, como a agricultura intensiva (mecanizada) e a pastagem cultivada de larga escala.

A Tabela 2 (anexo) enumera os 10 municípios com os maiores índices de remanescentes. Os municípios situados na micro-região da Chapada dos Veadeiros apresentam INR mais elevado do que no restante do Estado de Goiás (média de 0,73).

Por outro lado, novos focos de desmatamentos, sobretudo nos municípios com grande área de remanescentes, têm sido observados com uma maior freqüência, geralmente associados às atividades carvoeiras na região Norte do Estado.

\section{Análise integrada do uso da terra vs.}

\section{Geomorfologia}


Dentre as variáveis que podemos empregar para uma melhor compreensão da ocupação humana no Cerrado goiano, destacase o estudo das formas do relevo ou a morfologia da superfície, figurando como um subsídio ao planejamento territorial.

Em Goiás, assim como em outros estados no bioma Cerrado, atividades como a agricultura em larga escala são preferencialmente realizadas em relevos relativamente planos com baixa dissecação (i.e. superfícies mais antigas com reduzido processo erosivo), além de uma declividade baixa e/ou moderada (não mais do que $15^{\circ}$ de inclinação). Estas superfícies no Cerrado, conhecidas por Chapadões, estão localizadas em altitudes entre 700 e 1200 metros, oferecendo, além da topografia plana, outras condições favoráveis à agricultura, como temperaturas e precipitação regulares, e solos desenvolvidos e bem drenados (ex. Latossolo). Por outro lado, a utilização destas áreas para tais fins tornou-se possível graças à chamada "tecnificação do campo", com avanços nas práticas agrícolas, maquinários e insumos em geral (sementes, adubos e defensivos químicos).

Em fato, neste estudo preliminar para Goiás observamos uma tendência da prática agrícola em tais tipos de superfície, sobretudo na Superfície Regional de Aplainamento II (presente em grande parte do território goiano), o que é demonstrado pelo gráfico de distribuição na figura 8. Este tipo de superfície é também a mais favorável para a ocupação urbana. À medida que caminhamos para as superfícies mais novas (SRA III e IV) e, portanto, com relevos mais instáveis (maior dissecação e declividade), verifica-se o predomínio de pastagens (Fig. 8).

Outras unidades geomorfológicas, como Morros e Colinas (MC) e as Zonas de Erosão Recuante (ZER), são menos favoráveis às práticas de agricultura e pastagem, por se tratarem de relevo irregular, em parte fortemente dissecado, ou com maior controle estrutural. Especificamente nestas unidades é que se encontram boa parte dos remanescentes de Cerrado em Goiás, com fisionomias adaptadas e, de certa forma, protegidas da ação antrópica devido a estes limitantes naturais do relevo.

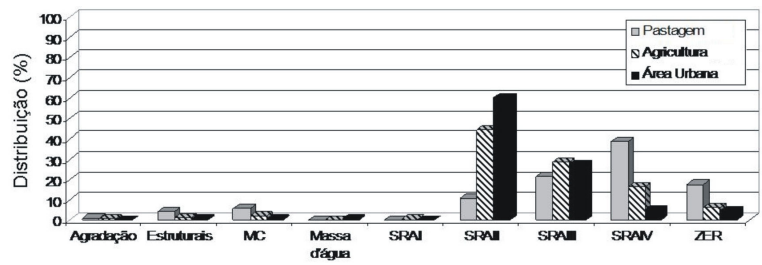

Figura 8 - Distribuição das classes de uso do solo em Goiás (pastagem, agricultura e área urbana) em função das categorias geomorfológicas. $\mathrm{MC}=$ morros e colinas; SRA = superfície regional de aplainamento; $\mathrm{ZER}=$ zona de erosão recuante.

Em relação aos remanescentes de vegetação e a respectiva unidade geomorfológica, e conforme observado no gráfico de distribuição da figura 9 , as unidades de topografia mais irregulares, isto é, com maior controle estrutural (ex. SRA IV, ZER e 
MC), apresentam maiores porcentagens de remanescentes de Cerrado, sobretudo para os estratos arbóreo e florestal. Tal fato se deve às condições naturais de solo e topografia destas áreas, pouco favoráveis ao uso da terra (pastagem e agricultura). Também é notável a elevada porcentagem de estrato herbáceo na classe SRA II, o que pode ser explicado, em parte, pela grande extensão desta unidade (terrenos planos), naturalmente com solos mais pobres em nutrientes (mais antigos), o que propicia a manutenção do grupo herbáceograminoso (Campo limpo e Campo sujo).

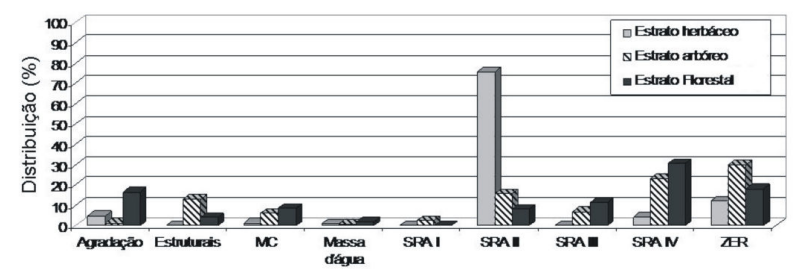

Figura 9 - Distribuição das classes de remanescentes (estratos herbáceo-arbustivo, arbóreo e florestal) em Goiás em função das categorias geomorfológicas. $\mathrm{MC}=$ morros $\mathrm{e}$ colinas; $\mathrm{SRA}=$ superfície regional de aplainamento; ZER = zona de erosão recuante.

Mais especificamente aos remanescentes florestais (Fig.9), estes permanecem em sua maioria na unidade SRA IV, sobretudo na região Nordeste do Estado de Goiás, onde a topografia e a declividade são bastante movimentadas (áreas com a maior altitude em Goiás). Nesta região situam-se algumas Unidades de Conservação (as maiores do Estado), além do Corredor Ecológico ParanáPerineus, projeto coordenado pelo IBAMA.

Carvalho, T. M. de, Ferreira, M. E. Bayer, M.

\section{CONSIDERAÇÕES FINAIS}

Neste artigo buscamos entender, ainda que de forma preliminar, a relação de variáveis físicas, como declividade e geomorfologia, com as classes de uso da terra comumente encontradas em Goiás. Verificamos também a relação destas categorias geomorfológicas com os remanescentes de vegetação. Fica evidenciada a influência do relevo tanto no atual estágio de preservação do Cerrado quanto na distribuição geográfica das classes de agricultura, pastagem e área urbana. Estudos complementares, já em andamento, em que se faz uma correlação com variáveis físicas e sócio-econômicas, a fim de se avaliar e prever as novas ocupações no Estado de Goiás e sua correspondência com as unidades geomorfológicas.

\section{REFERÊNCIAS}

ARRUDA, M.B. (org.). Ecossistemas Brasileiros. Brasília: Edições IBAMA, 2001. $49 \mathrm{p}$.

CARVALHO, T.M. Métodos de sensoriamento remoto aplicados à Geomorfologia. Rev. Geogr. Acadêmica, 1:4454, 2007.

EITEN, G. Cerrado's vegetation. In Cerrado: Caracterização, ocupação, e perspectivas, $2^{\text {nd }}$ ed, edited by M. N. Pinto, Ed. Universidade de Brasília, 1993. p.17-73.

FERREIRA, N.C.; BARCELOS, R.; FERREIRA, L.G. Transferência de informações ambientais geograficamente referenciadas no estado de Goiás: Subsídio à gestão territorial e ambiental integrada e 
democrática. In. Anais XII Simpósio Brasileiro de Sensoriamento Remoto, Goiânia, Brasil, 16-21 abril, INPE. 2005, p.2137-2144.

LATRUBESSE, E; CARVALHO, T. M. Geomorfologia de Goiás e Distrito Federal, Série Geologia e Mineracao, Secretaria de Indústria e Comércio. Governo do Estado de Goiás. Goiania, 2006. 88p.

MACHADO, R.B.; RAMOS NETO, M.B.; PEREIRA, P.G.P.; CALDAS, E.F.; GONÇALVES, D.A.; SANTOS, N.S.; TABOR, K.; STEININGER, M. 2004. Estimativas de perda da área do Cerrado brasileiro. Relatório técnico. Conservação Internacional, Brasília, DF. 25p. http://arruda.rits.org.br/notitia/reading/oeco/re ading/pdf/cerrado.pdf. Acesso em 3 de setembro de 2008.
MOREIRA, M.L.O. E FERREIRA, N.C. Base de dados geográficos para a gestão territorial e ambiental do estado de Goiás. In: Ferreira Jr., L. G. (Org.). Conservação da Biodiversidade e Sustentabilidade Ambiental em Goiás: Prioridades, Estratégias e Perspectivas. Goiânia, 2006.

MYERS, N. Biodiversity hotspots for conservation priorities. Nature, 403:853 -88 , 2000 .

RATTER, J.A.; BRIDGEWATER, S.; ATKINSON, R.; RIBEIRO, J.F. Analysis of the floristic composition of the Brazilian Cerrado vegetation II: comparison of the woody vegetation of 98 areas. Edinburgh J. of Bot., 53:153-180, 1996. 
Tabela 1 - Lista dos 10 municípios com o menor Índice Normalizado de Remanescente (INR) no Estado de Goiás, em ordem decrescente. Fonte: Ferreira et al. (2006).

\begin{tabular}{lllccc}
\hline Meso-região & Micro-região & \multicolumn{1}{c}{ Município } & \% Remanescente & \% Uso* & INR \\
\hline Centro Goiano & Anápolis & Damolândia & 0,00 & 100,00 & $-1,00$ \\
Centro Goiano & Goiânia & Goianira & 0,00 & 99,25 & $-1,00$ \\
& Vale do Rio & São João da & 0,12 & 99,88 & $-0,99$ \\
Sul Goiano & dos Bois & Paraúna & 0,12 & 99,69 & $-0,99$ \\
Centro Goiano & Anápolis & Brazabrantes & 0,64 & 99,04 & $-0,98$ \\
Sul Goiano & Meia ponte & Aloândia & 0,92 & 99,08 & $-0,98$ \\
Sul Goiano & Vale do Rio & Palminópolis & 0,95 & 99,05 & $-0,98$ \\
Centro Goiano & Anicuns & Adelândia & 0,95 & 99,01 & $-0,98$ \\
Centro Goiano & Anicuns & Firminópolis & 1,70 & 97,88 & $-0,96$ \\
Centro Goiano & Ceres & Ceres & 2,33 & 97,17 & $-0,95$ \\
Sul Goiano & Sudoeste de & Santa Helena de & Goiás & 2,33 \\
\hline
\end{tabular}

* Lagos e represas excluídos da análise. Dados referentes à escala cartográfica 1:250.000.

Tabela 2 - Lista dos 10 municípios com o maior Índice Normalizado de Remanescente (INR), em ordem decrescente. Fonte: Ferreira et al. (2006).

\begin{tabular}{|c|c|c|c|c|c|}
\hline Meso-região & Micro-região & Município & \% Remanescente & \% Uso* & $\overline{\text { INR }}$ \\
\hline Norte Goiano & $\begin{array}{l}\text { Chapada dos } \\
\text { Veadeiros }\end{array}$ & Teresina de Goiás & 98,44 & 1,56 & 0,96 \\
\hline Norte Goiano & $\begin{array}{l}\text { Chapada dos } \\
\text { Veadeiros }\end{array}$ & Cavalcante & 95,92 & 4,06 & 0,91 \\
\hline Norte Goiano & $\begin{array}{l}\text { Chapada dos } \\
\text { Veadeiros }\end{array}$ & Colinas do sul & 88,56 & 8,82 & 0,81 \\
\hline Norte Goiano & Porangatu & Campinaçú & 77,64 & 13,97 & 0,69 \\
\hline Norte Goiano & $\begin{array}{l}\text { Chapada dos } \\
\text { Veadeiros }\end{array}$ & $\begin{array}{l}\text { Alto Paraíso de } \\
\text { Goiás }\end{array}$ & 84,22 & 15,71 & 0,68 \\
\hline Norte Goiano & $\begin{array}{l}\text { Chapada dos } \\
\text { Veadeiros }\end{array}$ & $\begin{array}{l}\text { Monte alegre de } \\
\text { Goiás }\end{array}$ & 83,82 & 16,06 & 0,67 \\
\hline Leste Goiano & $\begin{array}{l}\text { Entorno de } \\
\text { Brasília }\end{array}$ & $\begin{array}{l}\text { Santo Antonio do } \\
\text { Descoberto }\end{array}$ & 81,26 & 18,73 & 0,62 \\
\hline Leste Goiano & Vão do Paraná & $\begin{array}{l}\text { Divinópolis de } \\
\text { Goiás }\end{array}$ & 77,50 & 21,87 & 0,56 \\
\hline Norte Goiano & $\begin{array}{l}\text { Chapada dos } \\
\text { Veadeiros }\end{array}$ & Nova Roma & 77,97 & 22,02 & 0,55 \\
\hline Norte Goiano & $\begin{array}{l}\text { Chapada dos } \\
\text { Veadeiros }\end{array}$ & $\begin{array}{l}\text { São João } \\
\text { D'aliança }\end{array}$ & 74,71 & 25,25 & 0,49 \\
\hline
\end{tabular}

* Lagos e represas excluídos da análise. Dados referentes à escala cartográfica 1:250.000. 